\title{
Disparities in the experience and treatment of dental caries among children aged 9-18 years: the cross-sectional study of Korean National Health and Nutrition Examination Survey (2012-2013)
}

\author{
Juyeong Kim ${ }^{1,2}$, Young Choi ${ }^{1,2}$, Sohee Park ${ }^{2,3}$, Jeong Lim Kim¹,2 , Tae-Hoon Lee ${ }^{1,2}$, Kyoung Hee Cho ${ }^{1,2}$
} and Eun-Cheol Park ${ }^{2,4^{*}}$

\begin{abstract}
Background: The aim of this study is to examine the association between parental socioeconomic status (SES) and the experience as well as treatment of dental caries among children aged 9 to 18 years.

Methods: Data from 1253 children aged 9-18 years from the Korean National Health and Nutrition Examination Survey (2012-2013) were analyzed. Parental socioeconomic status was measured using household income level and maternal educational level. The decayed, missing, and filled teeth (DMFT) index was used to measure experience of dental caries (DMFT $\geq 1$ ). Non-treatment of dental caries was measured according to whether the participants who experienced dental caries used a dental service at a dental clinic to treat caries during the previous year. Logistic regression was used to investigate the association between parental socioeconomic status and the experience of dental caries as well as the association between parental socioeconomic status and the non-treatment of dental caries among children that have experienced caries.

Results: A total of 808 subjects (64.5\%) experienced dental caries among 1253 participants, and 582 of these 808 subjects (72.0 \%) did not receive treatment among those having experience of dental caries. Parental socioeconomic status was not associated with experience of dental caries. However, those from low- and middle-income households were less likely to receive treatment than those from high-income households (odds ratio [OR] 2.11 [95\% confidence interval (Cl) 1.16-3.86], OR 2.14 [95 \% Cl 1.27-3.62]). In particular, those from lowand middle-income households who had regular dental checkups were more likely to have untreated caries than those from high-income households (OR 3.58 [95 \% Cl 1.25-10.24]).
\end{abstract}

Conclusions: This study demonstrates the parental household income-related disparities in children's dental health treatment. Efforts should be made to lower financial barriers to dental health services, particularly among those from low-income households, in order to reduce dental health disparities in the treatment of caries in children.

Keywords: Access to oral care, Socioeconomic status, Dental caries, DMFT, Dental public health

\footnotetext{
* Correspondence: ECPARK@yuhs.ac

${ }^{2}$ Institute of Health Services Research, Yonsei University, Seoul, Republic of

Korea

${ }^{4}$ Department of Preventive Medicine, Yonsei University College of Medicine,

50 Yonsei-roSeodaemun-gu, Seoul 120-752, Republic of Korea

Full list of author information is available at the end of the article
} 


\section{Background}

Socio-economic status (SES) has been identified as a predictor for oral health [1]. Social gradients exist between dental disease and income, education, region and race/ethnicity $[2,3]$. According to previous studies, there is a global association between SES and the prevalence of dental disease [4]. Dental disease tends to occur more frequently among individuals with social and/or financial hardships [5]. There is a previous study found that individuals with low income and low education are more likely to have poor oral health than those with a higher level of income and education [6]. This ongoing global problem extends to not only the incidence but also the management of disease [7]. Availability and accessibility to health care services have been reported as important factors in maintaining a good health status for all population levels. In a previous study, individuals' socioeconomic factors such as the level of household income and education were found to be related to a decrease in availability and accessibility of care $[5,8]$. Therefore, low household income and low education could be related to an unavailability and inaccessibility of dental care services. Although dental caries are not a life-threatening disease, the cost of treatment is considerable [9]. The limited capacity of the socially disabled hinders their access to proper and timely dental care, whereas access barriers exacerbate the poor dental health status of those with low SES levels [10].

Dental health disparities pass down to the next generation because children are affected by parental factors $[11,12]$. Dental caries are common among children worldwide [13]. Children with a deprived family background have a greater likelihood of having caries, and also tend to have more caries than their peers due to the impact of parental factors [14]. Moreover, oral health is linked to an individual's general health including low weight gain and poor child growth, because poor dental health affects the ability to eat [15]. According to a previous study, both poor dental health and lack of dental care were shown to be most obvious among United States children from socially disadvantaged family population [10]. Children from poverty-stricken and minority backgrounds are the fastest growing population of children, which indicates that high rates of dental disease will pose a significant societal and financial burden in the near future [10]. If the association between parental SES and the dental health as well as the poor use of dental treatment is maintained, then the inequality in oral health and dental care is projected to remain or increase [16-18].

Although the rapidly growing child population from socially disadvantaged family background [10], and the important of this issue, little has been known about the association between parental socioeconomic status and the experience as well as treatment of dental caries among Korean child population. One study on dental caries have recently emerged [19], but the experience of dental caries were analyzed only in a previous study. Therefore, this study was designed to investigate the impact of parental factors, particularly household income and parental education, on dental health status and access to dental health services in order to determine whether dental disparities in children exist or not. Previous studies reported a strong association between maternal education and children's dental health [20-22]. Therefore, maternal education level was used to measure parental education level.

This study tested two hypotheses with respect to children's dental health: (i) that lower parental SES is associated with a higher number of experience of dental caries in children; and (ii) that lower parental SES is associated with decreased treatment of dental caries among children experiencing dental caries. In this study, the connection between the level of parental SES and the number of children experiencing dental caries will be addressed first. Then, the relationship between parental SES and the non-treatment of dental caries among children having experienced dental caries will be investigated.

\section{Methods}

\section{Data and study population}

This study was conducted using secondary data from the 2012-2013 Korea National Health and Nutrition Examination Survey (KNHANES). The KNHANES is a nationally representative survey that uses standardized questionnaires based on an independent rolling sampling survey with a complex survey design to assess the health and nutritional status of the Korean population [23]. The KNHANES includes a health interview, a health examination (i.e., physical examination, clinical measurement, and tests), and a dietary interview. The oral examination of KNHANES was conducted at a mobile examination center by four trained dentists using a dental mirror under a fluorescent light [23]. The 2012-2013 KNHANES included data from 16,076 participants (8058 in 2012 and 8018 in 2013). The current study targeted children aged 9 to 18 years from this population to focus on health disparities in permanent teeth. Participants who were less than 9 or more than 18 years old were excluded from the study. Among 2074 children aged 9-18 years, samples with missing values of household income $(n=22)$, non-treatment of caries $(n=210)$, and missing values from other covariates (subjective oral health status $[\mathrm{n}=72]$, frequency of brushing teeth per day $[n=2]$, private insurance $[n=37]$, type of health insurance $[n=16]$, number of tools used for oral care $[n=$ 287]) were excluded. Parents with missing information 
for education level $(n=175)$ were also excluded. Ultimately, 1253 children within 905 households were included. The Institutional Review Board (IRB) of the Korea Centers for Disease Control and Prevention (KCDC) provided formal ethics approval for the KNHANES data sets (IRB approval number 2012-01EXP-01-2C for 2012 and 2013-07CON-03-4C for 2013).

\section{Measurements}

The current or historical experience of dental caries and the non-treatment of caries among children experiencing caries were chosen as the dependent variables. The experience of dental caries was based on the DMFT (i.e., decayed, missing due to caries, and previously filled teeth) scoring variable from the children's dental examination survey. The DMFT index is a dental caries diagnostic criteria developed by the WHO [24]. The DMFT index, which is a well-known and significant indicator of the dental health of the individual [25], indicates the number of decayed, missing, and filled teeth in the permanent dentition. This index therefore reflects a combination of untreated and treated caries [2]. DMFT scores were obtained by trained dentists using a dental mirror under a fluorescent light [23]. The value of this index was dichotomized into two categories: current or historical experience of caries (DMFT $\geq 1$ ) or having never experienced caries $(\mathrm{DMFT}=0)$. Access to treatment for dental caries was assessed via a question that asked whether the participants have used a dental service at a dental clinic to treat caries for a year (Yes/No), and it was dichotomized into two categories: treatment of caries or non-treatment of caries.

The independent variables were related to parental SES (household income level and maternal educational level), which was obtained via the survey questionnaire. Previous studies reported a strong association between maternal factors and children's dental health [20, 21]. Therefore, maternal factors such as education level were used to measure parental SES. Household income level was based on values from the household quartile, which was defined as those who live together and share livingrelated expenditures. Household income was measured as equalized gross household income per month. The equivalent household income was calculated by dividing the monthly household income by the square root of the number of household members and grouping the results into four quartiles: low $(<710,000 \mathrm{KRW}$ in 2012; $<750,000 \mathrm{KRW}$ in 2013), mid-low (710,000-1,470,000 $\mathrm{KRW}$ in 2012; 750,000-1,500,000 KRW in 2013), midhigh $(1,480,000-2,410,000 \mathrm{KRW}$ in 2012; 1,510,000$2,460,000 \mathrm{KRW}$ in 2013), and high (KRW $\geq 2,420,000$ in 2012; $K R W \geq 2,470,000$ in 2013). In our study, the low and mid-low groups were combined into one level (i.e., a single low-income household level), and the mid-high household income level was used as the middle-income household level. Therefore, three levels of household income (high, middle, and low) were analyzed in this study. For maternal education level, the highest level of education of the mother of the participant was used. Parental education level had three categories: elementary school graduate or lower, middle or high school graduate, and some college/university or higher.

Several covariates were used for adjustment. The demographic covariates in this study included sex, age, year, region of residence (urban/rural), type of health insurance (NHI or Medical Aid), and private insurance (yes or no). Several confounding variables that were related to dental health behaviors were also included: self-rated dental health status (high, medium, low); previous experience with preventive dental care in the past year, including sealant, fluorine coating, and dental scaling (yes or no); frequency of daily teeth brushing per day $(0-1$ or $\geq 2)$; number of tools used for oral care $(0$ or $\geq 1)$; and DMFT score $(0$ or $\geq 1)$. To determine the frequency of regular dental check-ups, participants were asked the following question: "Did you have a regular dental check-up within 1 year prior to the interview? (yes or no)." We defined the term "regular dental check-up" as a visit to a dental office more than once a year for the purpose of sustaining a healthy oral state despite the absence of an apparent dental problem. This definition of a regular dental check-up was also used in the previous study [26].

\section{Statistical analysis}

We used a chi-squared test for binary variables and the Wilcoxon Mann-Whitney $U$ test for ordinary variables to calculate the frequency and proportion of each variable. A logistic regression was conducted on the weighted data to generate one model containing all the variables of interest as well as potential covariates. Two logistic regressions were conducted to test each of the two hypotheses in this study. The first logistic regression was conducted on the full dataset to determine the association between parental SES and the experience of caries in their child. The second regression was conducted to determine the association between parental SES and the non-treatment of caries among the children who have experienced dental caries (DMFT $\geq 1$ ). All analyses were conducted in SAS Version 9.3 (SAS Institute, Inc., Cary, NC, USA).

\section{Results}

Table 1 summarizes the general characteristics of the children included in this study. A total of 1,253 participants were included in the initial dataset. Of these participants $(n=1,253), 808 \quad(64.5 \%)$ had experienced dental caries, and 445 (35.5 \%) had not experienced 
Table 1 General characteristics and health behaviors of children aged 9-18 years with incidents and non-treatment of caries

\begin{tabular}{|c|c|c|c|c|c|c|c|c|c|c|c|c|}
\hline \multirow[t]{4}{*}{ Variables } & \multirow[t]{4}{*}{$N$} & \multirow[t]{4}{*}{$\%^{c}$} & \multirow{2}{*}{\multicolumn{5}{|c|}{$\frac{\text { Experience of caries }^{\mathrm{a}}}{(n=1253)}$}} & \multicolumn{5}{|c|}{ Non-treatment ${ }^{b}(\mathrm{DMFT} \geq 1)$} \\
\hline & & & & & & & & \multicolumn{5}{|c|}{$(n=808)$} \\
\hline & & & \multicolumn{2}{|c|}{ Yes (DMFT $\geq 1)$} & \multicolumn{2}{|c|}{ No $(\mathrm{DMFT}=0)$} & \multirow[b]{2}{*}{ P } & \multicolumn{2}{|l|}{ Yes } & \multicolumn{2}{|l|}{ No } & \multirow[b]{2}{*}{$P$} \\
\hline & & & $\bar{N}$ & $\%^{d}$ & $\bar{N}$ & $\%^{d}$ & & $\bar{N}$ & $\%^{\mathrm{e}}$ & $\bar{N}$ & $\%^{\mathrm{e}}$ & \\
\hline At the household level (1,253 children in 905 households) & 1253 & 100 & 808 & 64.5 & 445 & 35.5 & & 582 & 72.0 & 226 & 28.0 & \\
\hline \multicolumn{13}{|l|}{ Household income level } \\
\hline Low & 431 & 34.4 & 279 & 64.7 & 152 & 35.3 & 0.976 & 217 & 77.8 & 62 & 22.2 & 0.005 \\
\hline Middle & 399 & 31.8 & 258 & 64.7 & 141 & 35.3 & & 188 & 72.9 & 70 & 27.1 & \\
\hline High & 423 & 33.8 & 271 & 64.1 & 152 & 35.9 & & 177 & 65.3 & 94 & 34.7 & \\
\hline \multicolumn{13}{|l|}{ Maternal education level } \\
\hline Elementary school graduate or lower & 37 & 3 & 26 & 70.3 & 11 & 29.7 & 0.022 & 22 & 84.6 & 4 & 15.4 & 0.114 \\
\hline Middle or high school graduate & 766 & 61.1 & 514 & 67.1 & 252 & 32.9 & & 377 & 73.4 & 137 & 26.7 & \\
\hline Some college or university graduate & 450 & 35.9 & 268 & 59.6 & 182 & 40.4 & & 183 & 68.3 & 85 & 31.7 & \\
\hline \multicolumn{13}{|l|}{ At the children level } \\
\hline \multicolumn{13}{|l|}{ Sex } \\
\hline Male & 668 & 53.3 & 387 & 57.9 & 281 & 42.1 & $<.0001$ & 304 & 78.6 & 83 & 21.5 & 0.002 \\
\hline Female & 585 & 46.7 & 421 & 52.1 & 164 & 28.0 & & 278 & 66.0 & 143 & 34.0 & \\
\hline \multicolumn{13}{|l|}{ Age } \\
\hline 9 to 12 years & 432 & 34.5 & 200 & 46.3 & 232 & 53.7 & $<.0001$ & 131 & 65.5 & 69 & 34.5 & 0.056 \\
\hline 13 to 15 years & 445 & 35.5 & 310 & 69.7 & 135 & 30.3 & & 232 & 74.8 & 78 & 25.2 & \\
\hline 16 to 18 years & 376 & 30 & 298 & 79.3 & 78 & 20.7 & & 219 & 73.5 & 79 & 26.5 & \\
\hline \multicolumn{13}{|l|}{ Region of residence } \\
\hline Urban & 1028 & 82 & 665 & 64.7 & 363 & 35.3 & 0.810 & 488 & 73.4 & 177 & 26.6 & 0.388 \\
\hline Rural & 225 & 18 & 143 & 63.6 & 82 & 36.4 & & 94 & 65.7 & 49 & 34.3 & \\
\hline \multicolumn{13}{|l|}{ Type of health insurance } \\
\hline $\mathrm{NHI}$ & 1214 & 96.9 & 779 & 64.2 & 435 & 35.8 & 0.133 & 561 & 72.0 & 218 & 28.0 & 0.272 \\
\hline Medical aid & 39 & 3.1 & 29 & 74.4 & 10 & 25.6 & & 21 & 72.4 & 8 & 27.6 & \\
\hline \multicolumn{13}{|l|}{ Private insurance } \\
\hline Yes & 1104 & 88.1 & 696 & 63.0 & 408 & 37.0 & 0.003 & 497 & 71.4 & 199 & 28.6 & 0.713 \\
\hline No & 149 & 11.9 & 112 & 75.2 & 37 & 24.8 & & 85 & 75.9 & 27 & 24.1 & \\
\hline \multicolumn{13}{|l|}{ Self-rated perception of dental health status } \\
\hline High & 247 & 19.7 & 132 & 53.4 & 115 & 46.6 & $<.0001$ & 100 & 75.8 & 32 & 24.2 & 0.580 \\
\hline Middle & 733 & 58.5 & 466 & 63.6 & 267 & 36.4 & & 332 & 71.2 & 134 & 28.8 & \\
\hline Low & 273 & 21.8 & 210 & 76.9 & 63 & 23.1 & & 150 & 71.4 & 60 & 28.6 & \\
\hline Experience of preventive dental care in the past year & & & & & & & & & & & & \\
\hline Yes & 121 & 9.7 & 73 & 60.3 & 48 & 39.7 & 0.882 & 42 & 57.5 & 31 & 42.5 & 0.011 \\
\hline No & 1132 & 90.3 & 735 & 64.9 & 397 & 35.1 & & 540 & 73.5 & 195 & 26.5 & \\
\hline Frequency of teeth brushing per day & & & & & & & & & & & & \\
\hline $0-1$ & 109 & 8.7 & 70 & 64.2 & 39 & 35.8 & 0.892 & 61 & 87.1 & 9 & 12.9 & 0.007 \\
\hline $2 \leq$ & 1144 & 91.3 & 738 & 64.5 & 406 & 35.5 & & 521 & 70.6 & 217 & 29.4 & \\
\hline Number of tools used for oral care & & & & & & & & & & & & \\
\hline None & 864 & 69 & 532 & 61.6 & 332 & 38.4 & 0.009 & 387 & 72.7 & 145 & 27.3 & 0.143 \\
\hline One or more & 389 & 31.1 & 276 & 71.0 & 113 & 29.1 & & 195 & 70.7 & 81 & 29.4 & \\
\hline
\end{tabular}

Regular checkups for oral care 
Table 1 General characteristics and health behaviors of children aged 9-18 years with incidents and non-treatment of caries (Continued)

\begin{tabular}{|c|c|c|c|c|c|c|c|c|c|c|c|c|}
\hline Yes & 597 & 47.7 & 382 & 64.0 & 215 & 36.0 & 0.906 & 227 & 59.4 & 155 & 40.6 & $<.0001$ \\
\hline No & 656 & 52.4 & 426 & 64.9 & 230 & 35.1 & & 355 & 83.3 & 71 & 16.7 & \\
\hline \multicolumn{13}{|c|}{ DMFT score } \\
\hline 0 & 445 & 35.5 & 0 & 0.0 & 445 & 100.0 & $<.0001$ & & & & & \\
\hline $1 \leq$ & 808 & 64.5 & 808 & 100.0 & 0 & 0.0 & & 582 & 72.0 & 226 & 28.0 & $<.0001$ \\
\hline \multicolumn{13}{|l|}{ Year } \\
\hline 2012 & 509 & 40.6 & 369 & 72.5 & 140 & 27.5 & $<.0001$ & 266 & 72.1 & 103 & 27.9 & 0.406 \\
\hline 2013 & 744 & 59.4 & 439 & 59.0 & 305 & 41.0 & & 316 & 72.0 & 123 & 28.0 & \\
\hline
\end{tabular}

${ }^{a}$ Represents the distribution of those with experience of dental caries (DMFT $\left.\leq 1\right)$, based on a total of 1253 children

${ }^{b}$ Represents the distribution of those who did not receive treatment of dental caries among those with experience of dental caries (DMFT $\leq 1$ ), based on a total of 808 children

'Weighted column percent (\%) based on 1253 participants

Weighted row percent (\%) of experience of caries (DMFT $\geq 1$ ) based on 1253 participants

'Weighted row percent (\%) of non-treatment of caries based on 808 participants with experience of caries (DMFT $\geq 1$ )

dental caries. Among those who experienced caries $(n=$ 808), $582(72.0 \%)$ did not receive treatment for their dental caries, and $226(28.0 \%)$ received treatment for their dental caries. The 1253 participants were divided into low (34.4\%), middle (31.8 \%), and high (33.8 \%) income households, respectively. Those who having experience of caries $(P=0.976)$ was shown to be $64.7 \%$, $64.7 \%$, and $64.1 \%$ in low-, middle-, and high-income households, respectively. The non-treatment of caries among children having experienced caries $(P=0.005)$ was shown to be $77.8 \%, 72.9 \%$, and $65.3 \%$ in low-, middle-, and high-income households, respectively. Both experience and non-treatment of caries among children who experienced caries were most frequent in low- and middle-income households and least frequent in highincome households. Most children in this population had mothers with a middle- and high-school graduate education level (61.1\%).

Table 2 presents the results from the logistic regression analysis. Several other factors were associated with the experience of caries: female sex (OR 1.91 [95 \% CI 1.41-2.59]) and low self-rated dental health status (OR 2.95 [95 \% CI 1.77-4.92]). Low and middle-income household was strongly associated with the nontreatment of caries among children experiencing caries (low, OR 2.11 [95 \% CI 1.16-3.86]; middle OR 2.14 [95\% CI 1.27-3.62]). In addition, the non-treatment of caries was associated with female sex (OR 0.65 [95\% CI $0.45-0.95]$ ); brushing teeth less than once per day (OR 2.76 [95 \% CI 1.13-6.71]); and irregular dental checkups (OR 3.76 [95 \% CI 2.58-5.49]).

Table 3 shows a subgroup analysis of gender and regular dental checkups with respect to the household income level. A stepwise trend by income level was found for each variable, but it was only statistically significant with respect to regular dental checkups. A negative association was found between the household income level and non- treatment of caries among children experiencing caries (OR 3.58 [95 \% CI 1.25-10.24]) irrespective of regular dental checkups.

\section{Discussion}

This study examined two associations: (i) between parental SES and the experience of dental caries and (ii) between parental SES and non-treatment of dental caries in those children having experienced dental caries. Parental factors were assumed to be associated with the experience and treatment of caries during childhood [27].

The findings from this study, however, found only partial associations between parental SES factors and dental health inequalities. In particular, parental SES factors appeared to influence the non-treatment but not the experience of dental caries. The household income level was the sole factor in this association. Although previous studies have linked children's dental health status and maternal education level, no statistically significant association was observed in this study $[15,20]$. The findings of this study therefore suggest that children who have experienced dental caries in low- and middle-income households are more likely to be associated with nontreatment than those from high-income households. In particular, those from low- and middle-income households who had regular dental checkups were more likely to have untreated caries than those from high-income households.

The results of our study did not indicate any significant associations between parental SES, particularly lower household income and lower parental education level, and children's experience of caries. However, several previous studies did find associations between parental SES and experience of dental caries $[5,10,19,28$, 29]. In studies in the United states and Brazil, both lower household income and lower education level of the caregiver are likely associated with experience of 
Table 2 Odds ratios for factors associated with the incidents and non-treatment of caries

\begin{tabular}{|c|c|c|c|c|c|c|}
\hline \multirow[t]{3}{*}{ Variables } & \multicolumn{3}{|c|}{ DMFT $\geq 1$} & \multicolumn{3}{|c|}{ Non-treatment (DMFT $\geq 1)$} \\
\hline & \multicolumn{3}{|c|}{$(N=1253)$} & \multicolumn{3}{|c|}{$(N=808)$} \\
\hline & $\mathrm{OR}$ & \multicolumn{2}{|c|}{$95 \% \mathrm{Cl}$} & $\mathrm{OR}$ & \multicolumn{2}{|c|}{$95 \% \mathrm{Cl}$} \\
\hline \multicolumn{7}{|l|}{ Household income level } \\
\hline Low & 0.96 & 0.63 & 1.47 & 2.11 & 1.16 & 3.86 \\
\hline Middle & 0.95 & 0.64 & 1.40 & 2.14 & 1.27 & 3.62 \\
\hline High & 1.00 & & & 1.00 & & \\
\hline \multicolumn{7}{|l|}{ Maternal education level } \\
\hline Elementary school graduate or lower & 1.15 & 0.55 & 2.40 & 2.59 & 0.67 & 10.00 \\
\hline Middle or high school graduate & 1.34 & 0.99 & 1.81 & 0.99 & 0.61 & 1.59 \\
\hline Some college or university graduate & 1.00 & & & 1.00 & & \\
\hline \multicolumn{7}{|l|}{ Sex } \\
\hline Male & 1.00 & & & 1.00 & & \\
\hline Female & 1.91 & 1.41 & 2.59 & 0.65 & 0.45 & 0.95 \\
\hline \multicolumn{7}{|l|}{ Age } \\
\hline 9 to 12 years & 1.00 & & & 1.00 & & \\
\hline 13 to 15 years & 2.47 & 1.79 & 3.43 & 1.61 & 0.91 & 2.83 \\
\hline 16 to 18 years & 3.63 & 2.44 & 5.41 & 2.02 & 1.10 & 3.73 \\
\hline \multicolumn{7}{|l|}{ Region of residence } \\
\hline Urban & 1.00 & & & 1.00 & & \\
\hline Rural & 0.95 & 0.56 & 1.60 & 0.70 & 0.41 & 1.20 \\
\hline \multicolumn{7}{|l|}{ Type of health insurance } \\
\hline $\mathrm{NHI}$ & 1.00 & & & 1.00 & & \\
\hline Medical aid & 1.39 & 0.61 & 3.17 & 0.43 & 0.18 & 1.03 \\
\hline \multicolumn{7}{|l|}{ Private insurance } \\
\hline Yes & 1.00 & & & 1.00 & & \\
\hline No & 1.69 & 1.02 & 2.82 & 1.05 & 0.55 & 2.02 \\
\hline \multicolumn{7}{|l|}{ Self-rated perception of dental health status } \\
\hline High & 1.00 & & & 1.00 & & \\
\hline Middle & 1.81 & 1.26 & 2.59 & 0.83 & 0.48 & 1.46 \\
\hline Low & 2.95 & 1.77 & 4.92 & 0.87 & 0.45 & 1.67 \\
\hline \multicolumn{7}{|c|}{ Experience of preventive dental care in the past year } \\
\hline Yes & 1.00 & & & 1.00 & & \\
\hline No & 0.98 & 0.60 & 1.59 & 1.20 & 0.64 & 2.22 \\
\hline \multicolumn{7}{|l|}{ Frequency of teeth brushing per day } \\
\hline $0-1$ & 1.10 & 0.67 & 1.81 & 2.76 & 1.13 & 6.71 \\
\hline$\geq 2$ & 1.00 & & & 1.00 & & \\
\hline \multicolumn{7}{|l|}{ Number of tools used for oral care } \\
\hline 0 & 0.84 & 0.63 & 1.12 & 0.98 & 0.66 & 1.46 \\
\hline$\geq 1$ & 1.00 & & & 1.00 & & \\
\hline \multicolumn{7}{|l|}{ Regular checkups for oral care } \\
\hline Yes & 1.00 & & & 1.00 & & \\
\hline No & 0.78 & 0.57 & 1.07 & 3.76 & 2.58 & 5.49 \\
\hline \multicolumn{7}{|l|}{ DMFT score } \\
\hline 1 to 2 & & & & 1.00 & & \\
\hline
\end{tabular}


Table 2 Odds ratios for factors associated with the incidents and non-treatment of caries (Continued)

\begin{tabular}{|c|c|c|c|c|c|c|}
\hline 3 to 4 & & & & 0.98 & 0.58 & 1.65 \\
\hline 5 to 6 & & & & 0.47 & 0.27 & 0.83 \\
\hline $7 \leq$ & & & & 0.32 & 0.17 & 0.60 \\
\hline \multicolumn{7}{|l|}{ Year } \\
\hline 2012 & 1.00 & & & 1.00 & & \\
\hline 2013 & 0.72 & 0.50 & 1.02 & 1.28 & 0.81 & 2.00 \\
\hline
\end{tabular}

dental caries among children [5, 28]. Moreover, lower household income was associated with experience of dental caries among children in another study in the US as well as a domestic study [10, 19]. In a study in Japan, a longer maternal education period was related to a decreased risk of dental caries among children, although there was no association with household income [29]. There are some differences between our study and these previous studies that may explain this discrepancy. First, as the two different dependent variables cover different lengths of time period, this may have led to unalike results. One previous study based on the same KNHANES data reported lower household income was related to experience of dental caries among children. In the study, the number of caries at the moment of the survey were used as the dependent variable rather than including previous occurrences [19], which may explain the discrepancy in findings between these two studies. The DMFT score in the

Table 3 Odds ratios for untreated children aged 9-18 years according to household income

\begin{tabular}{|c|c|c|c|c|c|c|c|}
\hline \multirow[t]{2}{*}{ Variables } & & \multicolumn{3}{|c|}{$\mathrm{DMFT} \geq 1$} & \multicolumn{3}{|c|}{ Non-treatment (DMFT $\geq 1)$} \\
\hline & & \multirow[t]{2}{*}{$\mathrm{aOR}^{\mathrm{a}}$} & \multicolumn{2}{|c|}{$95 \% \mathrm{Cl}$} & \multirow[t]{2}{*}{$\mathrm{aOR}^{\mathrm{a}}$} & \multicolumn{2}{|c|}{$95 \% \mathrm{Cl}$} \\
\hline \multicolumn{6}{|l|}{ Gender } & & \\
\hline \multirow[t]{3}{*}{ Male } & Low & 1.47 & 0.62 & 3.48 & 2.46 & 1.08 & 5.61 \\
\hline & Middle & 0.86 & 0.55 & 1.34 & 2.01 & 0.92 & 4.39 \\
\hline & High & 1.00 & & & 1.00 & & \\
\hline \multirow[t]{3}{*}{ Female } & Low & 1.57 & 0.50 & 4.92 & 1.68 & 0.86 & 3.31 \\
\hline & Middle & 0.98 & 0.57 & 1.68 & 2.15 & 1.18 & 3.92 \\
\hline & High & 1.00 & & & 1.00 & & \\
\hline \multicolumn{8}{|c|}{ Regular checkups for oral care } \\
\hline \multirow[t]{3}{*}{ Yes } & Low & 1.87 & 0.71 & 4.95 & 3.58 & 1.25 & 10.24 \\
\hline & Middle & 1.21 & 0.75 & 1.95 & 2.26 & 1.37 & 3.71 \\
\hline & High & 1.00 & & & 1.00 & & \\
\hline \multirow[t]{3}{*}{ No } & Low & 1.19 & 0.52 & 2.74 & 1.74 & 0.32 & 9.60 \\
\hline & Middle & 0.74 & 0.45 & 1.21 & 1.65 & 0.83 & 3.27 \\
\hline & High & 1.00 & & & 1.00 & & \\
\hline
\end{tabular}

DMFT decayed missing and filled teeth, $a O R$ adjusted odds ratio, $\mathrm{Cl}$ confidence interval

${ }^{a}$ Adjusted for age, year, private insurance, satisfaction of dental health care, frequency of teeth brushing teeth per day, experience of preventive dental care in the past year, number of tools used for oral care, and DMFT score current study covered a longer time period due to the inclusion of past and present caries and included the current treatment and disease status, the dependent variable in our study may have been affected by other factors. Parental SES which has changed during the period of growth could affected as well. In addition, there has been Korean government-funded efforts to reduce the incidents of caries among children via the promotion of preventive dental health such as community water fluoridation and dental health education by community health centers $[19,30]$, which may reduce the impact of parental SES on the incidence of dental caries. Fortunately, there has been a global movement to improve children's dental health [9].

Household income level likely contributed partially to the relationship between parental SES and nontreatment among children experiencing dental caries. This study found that children in low- and middleincome level households were more likely to not have received treatment of dental caries than those with high-household incomes. This finding was consistent with previous studies in the US and Korea [5, 10, 31] and can be explained by the healthcare policy in Korea. Although universal health coverage through the Korean National Health Insurance (KNHI) was designed to reduce the gap between socioeconomic classes in terms of accessibility and availability to healthcare services, the limited benefit coverage of the KNHI is known to be a problem, causing high economic burden to lowincome patients $[32,33]$. The limited benefit coverage is mainly due to the high percentage of out-of-pocket payment and uncovered medical services [33]. The high costs of out-of-pocket spending for medical services are a relatively greater burden to low-income households in terms of affordability. According to a previous study, economic burden due to spending costs for dental care was the most common concern among low-income groups who paid out-of-pocket [34]. In addition, the proportion of uncovered medical services is particularly large for Korean dental care services, resulting in severe economic disparities in the use of dental services [35]. Due to these factors, children from low- and middleincome households were associated with non-treatment of dental caries due to the economic burden from the 
use of medical services. This important finding highlights household income-related disparities in access to dental care services among children and also indicates the existence of a financial barrier to dental care services.

This study also assessed the impact of other factors, such as demographic characteristics and dental health behaviors, on the experience and non-treatment of dental caries. This study found that female children were more likely than male children to have dental caries; however, male children were more likely to experience non-treatment of dental caries than female children. This result suggests that females care more about their dental health than males despite the higher incidence of dental caries among females. No characteristics of dental health behavior were significantly associated with the incidents of dental caries except self-rated dental health status, which was negatively correlated with the incidents of dental caries in agreement with a previous study showing the association between low self-rated dental health status and more experience of caries $[6,36]$. This result suggests that more experience of caries can be associated with low self-rated dental health due to the tooth pain from current or previous caries. Although self-rated dental health status was not associated with the non-treatment of caries [37], several factors were significantly negatively associated with the non-treatment of dental caries including the frequency of tooth brushing and regular dental checkups. Our study found that infrequent brushing were more likely to be associated with non-treatment of caries, which is consistent with the finding of the previous study in Mexico [38]. This finding suggests that unhealthy dental care behaviors including infrequent tooth brushing among those having experience of caries can more easily lead to nontreatment of caries. In particular, our study found that children who did not have regular dental checkups were more likely to be related with non-treatment of dental caries, which is consistent with the findings of previous studies $[11,36]$.

In addition, our study found that children in low- and middle-income households who had regular dental checkups were more likely to not receive treatment than those in high-income households. In previous study, regular dental checkups were found to be a beneficial factor for professional diagnostic and prophylactic services, which are important for dental health [14, 39]. Therefore, children who had regular dental checkups also had information about their dental status based on diagnostic results, and they were able to make a clear decision regarding treatment before the disease deteriorated $[14,40]$. On the other hand, those who did not have regular dental checkups may not have been able to acknowledge whether they had any caries or not. However, our findings showed that although children who had regular dental checkups were more clearly aware of their medical needs, there was nevertheless a household income-related disparity in the treatment of caries. Our findings show that low-income children are more likely to not receive treatment of caries due to financial barriers even when children have already recognized that they need to receive treatment. Similarly, the lack of association between regular dental checkups and treatment of caries suggests that the current dental care services are not effective enough to lessen the financial barriers even for those with clear medical needs.

There are several limitations to this study. First, this study is based on cross-sectional data, which reduces the ability to determine an association between the factors and the experience and non-treatment of dental caries. Second, this study did not address the impact of paternal factors. Although the original study intended to use information from both parents, a significant amount of paternal information was missing from the data. Third, there was an association found between the self-rated perception of dental health status and untreated caries. A further study should be conducted to investigate the association between low self-rated health and untreated caries. Finally, this study did not analyze certain characteristic variables that are observed only in students, such as variables that address the length of time staying at school and the significant pressure to study faced by Korean students. A future study should consider such confounding variables to determine the influence on dental health, such as the stress associated with studying and the number of hours during which students are engaged in school activities.

This study reveals several important policy implications. First, the financial barriers to obtain restorative dental health services need to be eliminated. There exists an invisible barrier that prevents children from lowincome households from receiving treatment. It may be more difficult for low-income households to afford the financial burden of children's dental treatment, which may represent a significant proportion of the medical expenditure from their limited household income. The most effective policy would be a coverage increase in dental services. According to a previous study in Korea, the lack of coverage has resulted in access barriers and dental health disparities, and the wealthy receive the most advantage from the dental health gradient [41]. Second, the distribution of resources for dental services should focus more on the low-income households. Third, the lack of association between regular dental checkups and treatment of caries highlights the need for effective dental care, particularly for low-income household children. The need for dental health services increases as the level of household income decreases. Therefore, supportive policies with proper intervention 
can reduce the gap in dental care access between the high- and low-income households [1, 5, 10, 25].

\section{Conclusion}

This study revealed that parental SES-related inequalities were associated with the treatment of dental caries. In particular, those from low- and middle-income households who had regular dental checkups were more likely to have untreated caries than those from high-income households. There is a need to reduce household income-related disparities in children's dental health treatment. Through the findings presented here, we hope to contribute to the establishment of a dental health policy that reduces household income-related inequalities in dental care.

\section{Acknowledgments}

The authors appreciate the Yonsei University Institute of Health Services Research for its administrative support.

\section{Authors' contributions}

JK (the first author), YC (the second author), and EP (the corresponding author) contributed to the research design, data analysis, and interpretation of data. JLK, THL, and KHC carried out the interpretation of data and revision of the article. SP contributed to the revision of the article for solving statistical issues. JK and EP wrote the article. This manuscript has been read and approved by all authors and all authors agree to the submission of the manuscript.

\section{Competing interests}

The authors declare that they have no competing interests.

\section{Financial support}

This research received no specific grant from any funding agency in public, commercial or not-for-profit sectors.

\section{Author details}

${ }^{1}$ Department of Public Health, Graduate School, Yonsei University, Seoul, Republic of Korea. ${ }^{2}$ Institute of Health Services Research, Yonsei University, Seoul, Republic of Korea. ${ }^{3}$ Department of Biostatistics, Graduate School of Public Health, Yonsei University, Seoul, Republic of Korea. ${ }^{4}$ Department of Preventive Medicine, Yonsei University College of Medicine, 50 Yonsei-roSeodaemun-gu, Seoul 120-752, Republic of Korea.

Received: 27 June 2015 Accepted: 30 May 2016

Published online: 07 June 2016

\section{References}

1. Mejia G, Jamieson L, Ha D, Spencer A. Greater inequalities in dental treatment than in disease experience. J Dent Res. 2014;93(10):966-71.

2. Geyer S, Schneller T, Micheelis W. Social gradients and cumulative effects of income and education on dental health in the Fourth German Oral Health Study. Community Dent Oral Epidemiol. 2010;38(2):120-8.

3. Choi $Y$, Lee $S$. Does regional socioeconomic context affect the dental caries experience? A multilevel study of Korean adults. Eur J Oral Sci. 2011:119(4): 294-300.

4. Statistics. FIFoCaF: America's children: key national indicators of well-being, 2009. In: 2009: Federal Interagency Forum on Child and Family Statistics; 2009.

5. Edelstein BL. Disparities in oral health and access to care: findings of national surveys. Ambul Pediatr. 2002;2(2):141-7.

6. Sabbah W, Tsakos G, Chandola T, Sheiham A, Watt R. Social gradients in oral and general health. J Dent Res. 2007:86(10):992-6.

7. Wamala S, Merlo J, Boström G. Inequity in access to dental care services explains current socioeconomic disparities in oral health: the Swedish National Surveys of Public Health 2004-2005. J Epidemiol Community Health. 2006;60(12):1027-33.
8. lecovich E, Carmel S. Differences in accessibility, affordability, and availability (AAA) of medical specialists among three age-groups of elderly people in Israel. J Aging Health. 2009;21(5):776-97.

9. Centers for Disease Control and Prevention (CDC). Untreated dental caries (cavities) in children ages 2-19, United States. 2011. p. 9.

10. Edelstein $\mathrm{BL}$, Chinn $\mathrm{CH}$. Update on disparities in oral health and access to dental care for America's children. Acad Pediatr. 2009;9(6):415-9.

11. Reisine ST, Psoter W. Socioeconomic status and selected behavioral determinants as risk factors for dental caries. J Dent Educ. 2001;65(10):1009-16.

12. Peres MA, Peres KG, de Barros AJD, Victora CG. The relation between family socioeconomic trajectories from childhood to adolescence and dental caries and associated oral behaviours. J Epidemiol Community Health. 2007; 61(2):141-5.

13. Sheiham A, Alexander D, Cohen L, Marinho V, Moyses S, Petersen PE, Spencer J, Watt RG, Weyant R. Global oral health inequalities: task groupimplementation and delivery of oral health strategies. Adv Dent Res. 2011; 23(2):259-67.

14. US Department of Health Human Services. Oral health in America: a report of the Surgeon General. J Calif Dent Assoc. 2000;63:74-94.

15. Oliveira LB, Sheiham A, Bönecker M. Exploring the association of dental caries with social factors and nutritional status in Brazilian preschoo children. Eur J Oral Sci. 2008;116(1):37-43.

16. Moore KA, Redd Z, Burkhauser M, Mbwana K, Collins A. Children in poverty: Trends, consequences and policy options: Child Trends. 2002.

17. Petersen PE, Bourgeois D, Ogawa H, Estupinan-Day S, Ndiaye C. The global burden of oral diseases and risks to oral health. Bull World Health Organ. 2005;83(9):661-9.

18. Dye BA, Tan S, Smith V, Lewis B, Barker L, Thornton-Evans G, Eke P, BeltránAguilar E, Horowitz A, Li C. Trends in oral health status: United States, 1988 1994 and 1999-2004. Vital Health Stat. 2007:11(248):1-92.

19. Shin B, Jung S. Socio-economic inequalities in dental caries in Korea. J Korean Acad Oral Health. 2012;36(2):144-52.

20. Sufia S, Khan AA, Chaudhry S. Maternal factors and Child's dental health J Oral Health Comm Dent. 2009:3(3):45-8.

21. Marmot M. Social determinants of health inequalities. Lancet. 2005; 365(9464):1099-104

22. Kinirons M, McCabe M. Familial and maternal factors affecting the dental health and dental attendance of preschool children. Community Dent Health. 1995;12(4):226-9.

23. Oh K, Lee J, Lee B, Kweon S, Lee Y, Kim Y. Plan and operation of the 4th Korea national health and nutrition examination survey (KNHANES IV). Korean J Epidemiol. 2007;29(2):139-45.

24. World Health Organization: Oral Health Survey: Basic Method. In.; 1992.

25. Böhning D, Dietz E, Schlattmann P, Mendonca L, Kirchner U. The zero-inflated Poisson model and the decayed, missing and filled teeth index in dental epidemiology. J R Stat Soc Ser A Stat Soc. 1999:162(2):195-209.

26. Han DH, Kim DH, Kim MJ, Kim JB, Jung-Choi K, Bae KH. Regular dental checkup and snack-soda drink consumption of preschool children are associated with early childhood caries in Korean caregiver/preschool children dyads. Community Dent Oral Epidemiol. 2014:42(1):70-8.

27. Correa MB, Peres MA, Peres KG, Horta BL, Barros AJ, Demarco FF. Do socioeconomic determinants affect the quality of posterior dental restorations? A multilevel approach. J Dent. 2013;41(11):960-7.

28. Engelmann J, Tomazoni F, Oliveira M, Ardenghi T. Association between Dental Caries and Socioeconomic Factors in Schoolchildren-A Multilevel Analysis. Braz Dent J. 2016;27(1):72-8.

29. Tanaka K, Miyake Y, Sasaki S, Hirota Y. Socioeconomic status and risk of dental caries in Japanese preschool children: The Osaka Maternal and child health study. J Public Health Dent. 2013:73(3):217-23.

30. Federal Interagency Forum on Child and Family Statistics. America's children: key national indicators of well-being 2000. Washington (DC): United States Government Printing Office; 2000.

31. Ahn ES, Han JH. Measure of Unmet Dental Care Needs among Korean Adolescent. J Dent Hyg Sci. 2015;15(2):91-7.

32. Kim S, Huh S. Financial burden of health care expenditures and unmet needs by socioeconomic status. Korean Health Econ Rev. 2011;17(1):47-70.

33. Jeong $H$. Korea's National Health Insurance-lessons from the past three decades. Health Affairs. 2011;30(1):136-44.

34. Locker D, Quiñonez C, Maggirias J. Assessing income, dental insurance, and cost barriers to dental care. J Dent Res. 2009;88(Special Issue A):0650. 
35. Jeon JE, Chung WG, Kim NH. The reason of unmet dental need related socioeconomic status in Korea: Using the 4th Korea National Health and Nutritional Examination Survey. J Korean Acad Oral Health. 2012;36(1):73-81.

36. Sabbah W, Tsakos G, Sheiham A, Watt RG. The role of health-related behaviors in the socioeconomic disparities in oral health. Soc Sci Med. 2009; 68(2):298-303.

37. Bedos C, Levine A, Brodeur J-M. How people on social assistance perceive, experience, and improve oral health. J Dent Res. 2009;88(7):653-7.

38. Irigoyen ME, Maupome G, Mejia A. Caries experience and treatment needs in a 6-to 12-year-old urban population in relation to socio-economic status. Community Dent Health. 1999;16(4):245-9.

39. Murray JJ. Attendance patterns and oral health. Br Dent J. 1996;181(9):339-42.

40. American Academy of Pediatric Dentistry. American Academy of Pediatric Dentistry Council on Clinical Affairs Policy on early childhood caries (ECC): classifications, consequences, and preventive strategies. Pediatr Dent. 2006; 27(7 Suppl):31-43.

41. Shin H, Kim HD. Income related inequality of dental care utilization in Korea. Health Soc Welf Rev. 2006;26(1):69-93.

Submit your next manuscript to BioMed Central and we will help you at every step:

- We accept pre-submission inquiries

- Our selector tool helps you to find the most relevant journal

- We provide round the clock customer support

- Convenient online submission

- Thorough peer review

- Inclusion in PubMed and all major indexing services

- Maximum visibility for your research

Submit your manuscript at www.biomedcentral.com/submit
Biomed Central 